\title{
A dense network of dendritic cells populates the murine epididymis
}

\author{
Nicolas Da Silva ${ }^{1,2}$, Virna Cortez-Retamozo ${ }^{2}$, Hans-Christian Reinecker ${ }^{3}$, Moritz Wildgruber $^{2}$, \\ Eric Hill ${ }^{1,2}$, Dennis Brown ${ }^{1,2}$, Filip K Swirski ${ }^{2}$, Mikael J Pittet ${ }^{2}$ and Sylvie Breton ${ }^{1,2}$ \\ ${ }^{1}$ Program in Membrane Biology and Division of Nephrology, ${ }^{2}$ Center for Systems Biology and ${ }^{3}$ Gastrointestinal Unit \\ and Center for the Study of Inflammatory Bowel Disease, Massachusetts General Hospital and Harvard Medical \\ School, 185 Cambridge Street, CPZN 8.206, Boston, Massachusetts 02114-2790, USA
}

Correspondence should be addressed to N Da Silva at Program in Membrane Biology and Division of Nephrology, Center for Systems Biology, Massachusetts General Hospital and Harvard Medical School; Email: dasilva.nicolas@mgh.harvard.edu

\begin{abstract}
One of the most intriguing aspects of male reproductive physiology is the ability to generate spermatogenic cells - which are 'foreign' to the host - without triggering immune activation. After leaving the testis, spermatozoa enter the epididymis where they mature and are stored. In this study, we report a previously unrecognized dense network of dendritic cells (DCs) located at the base of the epididymal epithelium. This network was detected in transgenic mice expressing CD11c-EYFP and CX3CR1-GFP reporters. Epididymal DCs (eDCs) establish intimate interactions with the epithelium and project long dendrites between epithelial cells toward the lumen. We show that isolated eDCs express numerous leukocyte markers described previously in other organs that are in contact with the external environment, and present and cross-present ovalbumin to T cells in vitro. eDCs are, therefore, strategically positioned to regulate the complex interplay between immune tolerance and activation, a balance that is fundamental to male fertility.

Reproduction (2011) 141 653-663
\end{abstract}

\section{Introduction}

Although a significant proportion of male infertility cases are thought to have an immunological cause (Stedronska \& Hendry 1983, Pattinson \& Mortimer 1987, McLachlan 2002, Meinhardt \& Hedger 2010), the cellular and molecular basis of immune regulation in the epididymis - the site of sperm maturation and storage - remains poorly understood. The establishment and maintenance of male fertility requires close and tightly regulated interactions between the reproductive, endocrine, and immune systems. Spermatozoa acquire motility and the ability to fertilize an egg during their transit in the epididymis, a single, long, and convoluted duct with a large epithelial-luminal interface located downstream of the testis. Post-testicular sperm maturation involves numerous mechanisms mediated by the pseudostratified epithelium that lines the epididymis, including protein secretion and reabsorption, as well as fluid and ion exchanges (Da Silva et al. 2007, Cornwall 2009, Shum et al. 2009). One of the most striking characteristics of spermatozoa is their immunological status: post-meiotic germ cells start expressing new surface and intracellular molecules at puberty, long after the establishment of systemic immune tolerance. They are, therefore, foreigners in the environment in which they were produced (Fijak \& Meinhardt 2006, Hedger \& Hales 2006). Despite this apparent paradox, they are tolerated and even pampered all along the excurrent duct (efferent ducts, epididymis, vas deferens, and ejaculatory ducts), as they are prepared to face the challenging environment of the female genital tract. The immunological status of spermatozoa would not be particularly intriguing if the barriers lining the male reproductive system were totally efficient, but the physical separation between the immune system and the germ cells is far from perfect (Pelletier 1994, Pollanen \& Cooper 1994, Levy \& Robaire 1999, Hedger \& Hales 2006). In addition, the male reproductive tract is contiguous with the external environment and, therefore, continuously challenged by potential pathogenic microorganisms and viruses. Inflammation of the epididymis can cause obstruction or destruction of the duct leading to transient or permanent infertility (Chan \& Schlegel 2002, Cunningham \& Beagley 2008). Yet, the mechanisms that prevent the development of an autoimmune response against millions of autoantigenic spermatogenic cells and mature spermatozoa, while maintaining the ability to initiate efficient immune responses against pathogenic microorganisms and cancer cells, are still superficially understood. These mechanisms have been studied mostly in the testis (Meinhardt \& Hedger 2010), largely 
underestimating the immune function of the epididymis and the post-testicular environment in general. Intraepithelial lymphocytes and other immunocompetent cells have been observed in the epididymis (Ritchie et al. 1984, Nashan et al. 1989, 1990, 1993, Barratt et al. 1990, Tomlinson et al. 1992, Yeung et al. 1994, Hooper et al. 1995, Flickinger et al. 1997, Rossi \& Aitken 1997, Serre \& Robaire 1999), but the precise nature of these cells and their immunological properties remain to be elucidated. Dendritic cells (DCs), the specialized antigen-presenting cells (APCs) that are key regulators of immune responses in numerous organs (Banchereau \& Steinman 1998, Steinman et al. 2003, Steinman \& Banchereau 2007, Helft et al. 2010), are thought to be absent from the epididymal epithelium (Seiler et al. 2000). In this study, we describe a surprisingly extensive network of stellate cells visualized in the epididymis of CD11c-EYFP (Lindquist et al. 2004) and CX3CR1-GFP (Jung et al. 2000) reporter mice. Based on their striking dendriform morphology, their intimate interactions with the epididymal epithelium, their phenotype, and antigen-presenting capabilities, we named these cells 'epididymal DCs' (eDCs). eDCs and other cells from the mononuclear phagocyte system (MPS) are ideally positioned to play a major role in male reproductive physiology and pathophysiology. Unraveling their function in the unique environment constituted by the epididymis may also help to better understand the mechanisms of tolerance and autoimmunity in male reproductive function.

\section{Results}

\section{$C^{C D 11 c^{+}}$and CX3CR1 ${ }^{+}$DCs form a dense network localized at the base of the epididymal epithelium}

We examined $50 \mu \mathrm{m}$ sections of epididymis from CD11c-YFP and CX3CR1-GFP adult mice by fluorescence microscopy and generated large mosaic images representing complete sections of the entire organ (Fig. 1 and Supplementary Figures 1 and 2, see section on supplementary data given at the end of this article). The epididymis is a continuous tubule, but a portion of the body (or corpus), which is very narrow, is often absent from thick sections. The entire murine epididymis is heavily populated by a network of $\mathrm{CD} 11 \mathrm{C}-\mathrm{YFP}^{+}$and CX3CR1-GFP ${ }^{+}$DCs (Fig. 1a and b respectively), located mostly in the peritubular region (Fig. 1c and d). In the proximal epididymis, eDCs exhibit numerous ramifications that cover the basal side of the epithelium (Fig. 1d). To better examine the distribution and the morphology of eDCs, we generated high-magnification epifluorescence and confocal pictures of live (examined within $15 \mathrm{~min}$
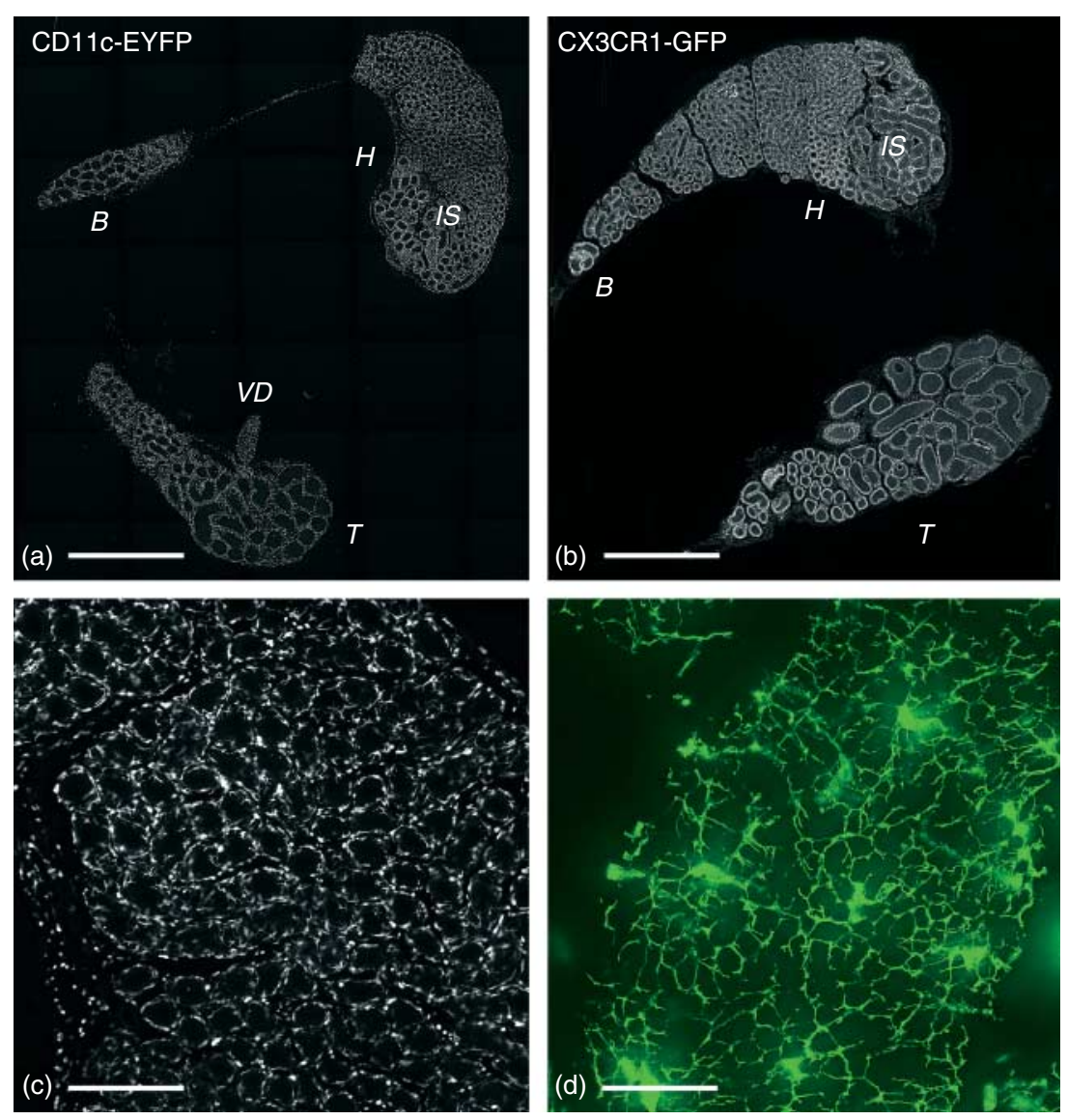

Figure 1 The epididymis is densely populated by CD $11 \mathrm{c}^{+}$and CX3CR ${ }^{+}$cells. (a and b) 'Mosaic' pictures of whole CD11c-EYFP and CX3CR1-GFP mouse epididymis sections respectively. IS, initial segments; $\mathrm{H}$, head (caput); B, body (corpus); $\mathrm{T}$, tail (cauda); VD, vas deferens. (c and d) Higher magnification pictures of the initial segments, showing numerous CD11c-EYFP ${ }^{+}$cells located at the periphery of the epididymal tubule. Bars $=2 \mathrm{~mm}$ (a and b), $250 \mu \mathrm{m}$ (c), and $50 \mu \mathrm{m}$ (d). High-resolution pictures for panels $\mathrm{a}$ and $\mathrm{b}$ are available online (Supplementary Figures 1 and 2, see section on supplementary data given at the end of this article). 

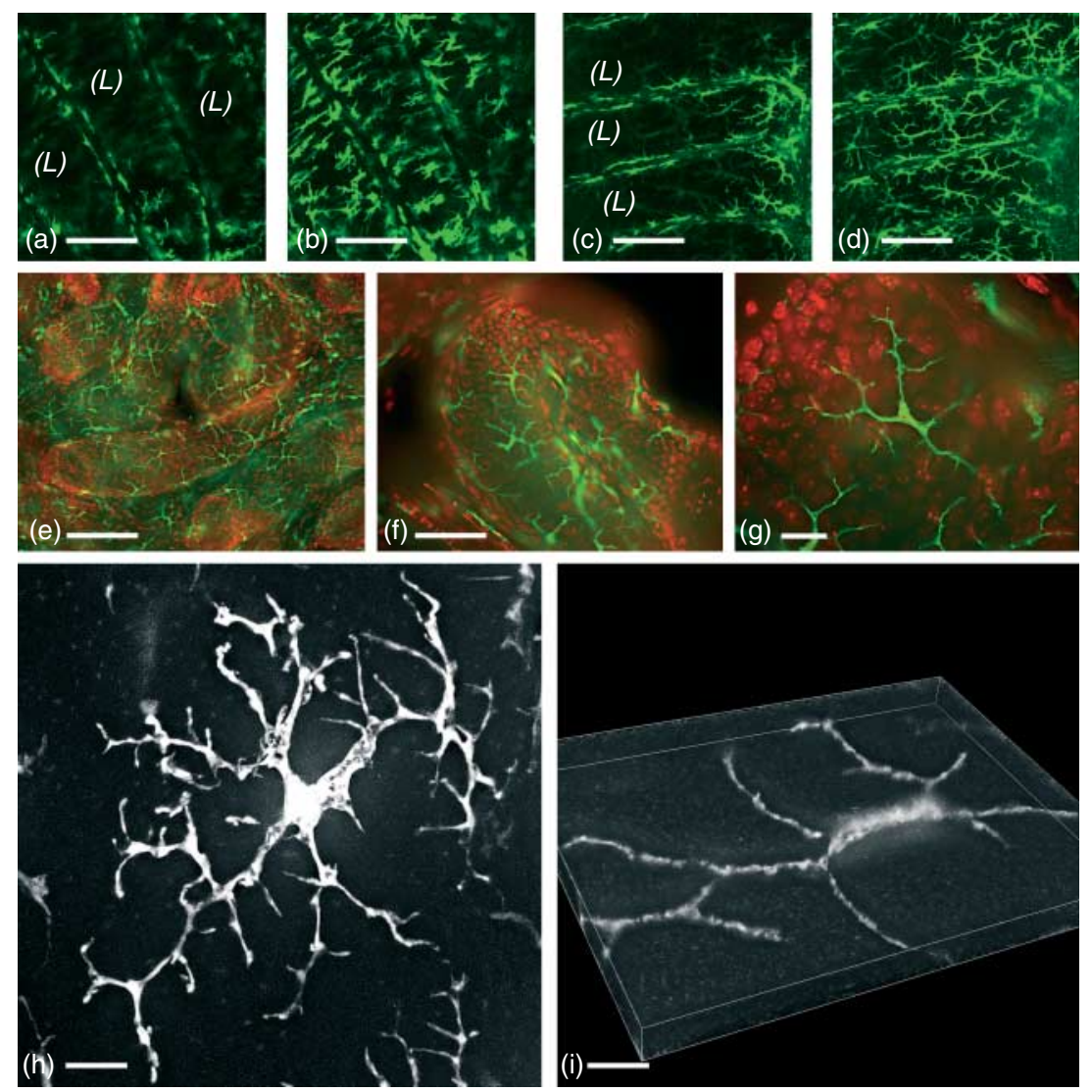

Figure 2 Epididymal $\mathrm{CD} 11 \mathrm{c}^{+}$and $\mathrm{CX} 3 \mathrm{CR} 1^{+}$cells are peritubular and have stellate/dendriform morphology. (a-d) Visualization of CX3CR1-GFP ${ }^{+}$ and CD11c-EYFP ${ }^{+}$eDCs using live cell confocal microscopy. Unfixed tissue slices were observed within 15 min after dissection. ( $\mathrm{a}$ and $\mathrm{b}$ ) and (c and d) represent two confocal planes of the same field in CD11C-EYFP and CX3CR1-GFP tissues respectively. The lumen $(\mathrm{L})$ is populated by spermatozoa that are invisible in these pictures; eDCs are located at the periphery of the epididymal tubule (e-g). Conventional fluorescence microscopy visualization of CX3CR1-GFP-positive eDCs (20, 40 , and $60 \times$ objectives respectively). Nuclei were stained (red) to better appreciate the organization of the tissue. (h and i) High-magnification pictures of CD11c-EYFP ${ }^{+}$cells in caput and cauda epididymis respectively showing the distinctive morphology of eDCs in these regions. Cells are more ramified in the caput compared with the cauda. Bars $=100(\mathrm{a}-\mathrm{e}), 50(\mathrm{f})$, and $10 \mu \mathrm{m}(\mathrm{g}-\mathrm{i})$. after dissection) and fixed tissue sections. Most, if not all, eDCs have a stellate/dendriform morphology and are located at the base of the epithelium (Fig. 2). CD11 $\mathrm{C}^{+}$ (Fig. 2a, b and $\mathrm{h}$ ) and CX3CR1 ${ }^{+}$(Fig. 2c-g) cell morphology and distribution appear very similar, but our microscopic analysis cannot rule out that these transgenes may, in fact, highlight several overlapping subsets of cells in the epididymis. In addition, eDCs are more ramified in the proximal epididymis (head, Fig. 2h) than in the distal segment (tail, Fig. 2i).

\section{eDCs project numerous intraepithelial processes in the proximal epididymis}

High-resolution fluorescence cross-section images (Fig. 3a and Supplementary Movie 1, see section on supplementary data given at the end of this article) revealed that eDCs project slender processes (diameter $<1 \mu \mathrm{m}$ ) between epithelial cells, toward the lumen. Three-dimensional reconstruction showed that the DC bodies lie on the basal surface of the epithelium and send narrow projections that run along the basal axis of the epithelium (Fig. 3b). Perpendicular dendritic processes arise from these projections (Supplementary Movie 2, see section on supplementary data given at the end of this article) and plunge deeply between the epithelial cells. A single eDC can survey a considerable region (up to $10000 \mu \mathrm{m}^{2}$; Figs $2 \mathrm{~h}$ and $3 \mathrm{c}$ ) and can project up to 40 processes that penetrate the lateral compartment of the epithelium (Fig. 3d). Intraepithelial dendrites that extend toward the tight-junction barrier of the epithelium (visualized using TJP1 (also known as ZO-1) immunolabeling) are visible primarily in the initial segments (Fig. 3e). In the distal epididymis (tail), eDCs are flat and interact with the basal surface of the epithelium, but they do not project visible intraepithelial dendrites (Figs $2 \mathrm{i}$ and $3 \mathrm{f}$ ). Occasionally, some CD11c-GFP ${ }^{+}$and CX3CR ${ }^{+}$cells appear to be embedded within the epithelium rather than being exclusively peritubular (not shown).

\section{Phenotype of eDCs}

Next, we phenotyped eDCs with antibodies against surface markers typically used for the characterization of leukocytes and APCs (Choi et al. 2009, Ginhoux et al. 2009, Miloud et al. 2010). Our preliminary flow cytometry analyses showed that most epididymal CX3CR1-GFP ${ }^{+}$ cells express CD11C (Supplementary Figure 3, see section on supplementary data given at the end of this article). To exclude any possible abnormality of the phenotype and/or number of DCs in transgenic animals, we performed all the subsequent analyses with wild-type C57BL/6 mice. We identified two major populations of eDCs: CD11c ${ }^{+}$ $\mathrm{CD}_{103}{ }^{+}$eDCs and CD11c ${ }^{+} \mathrm{CD}_{103}{ }^{-}$eDCs (Fig. 4a). 

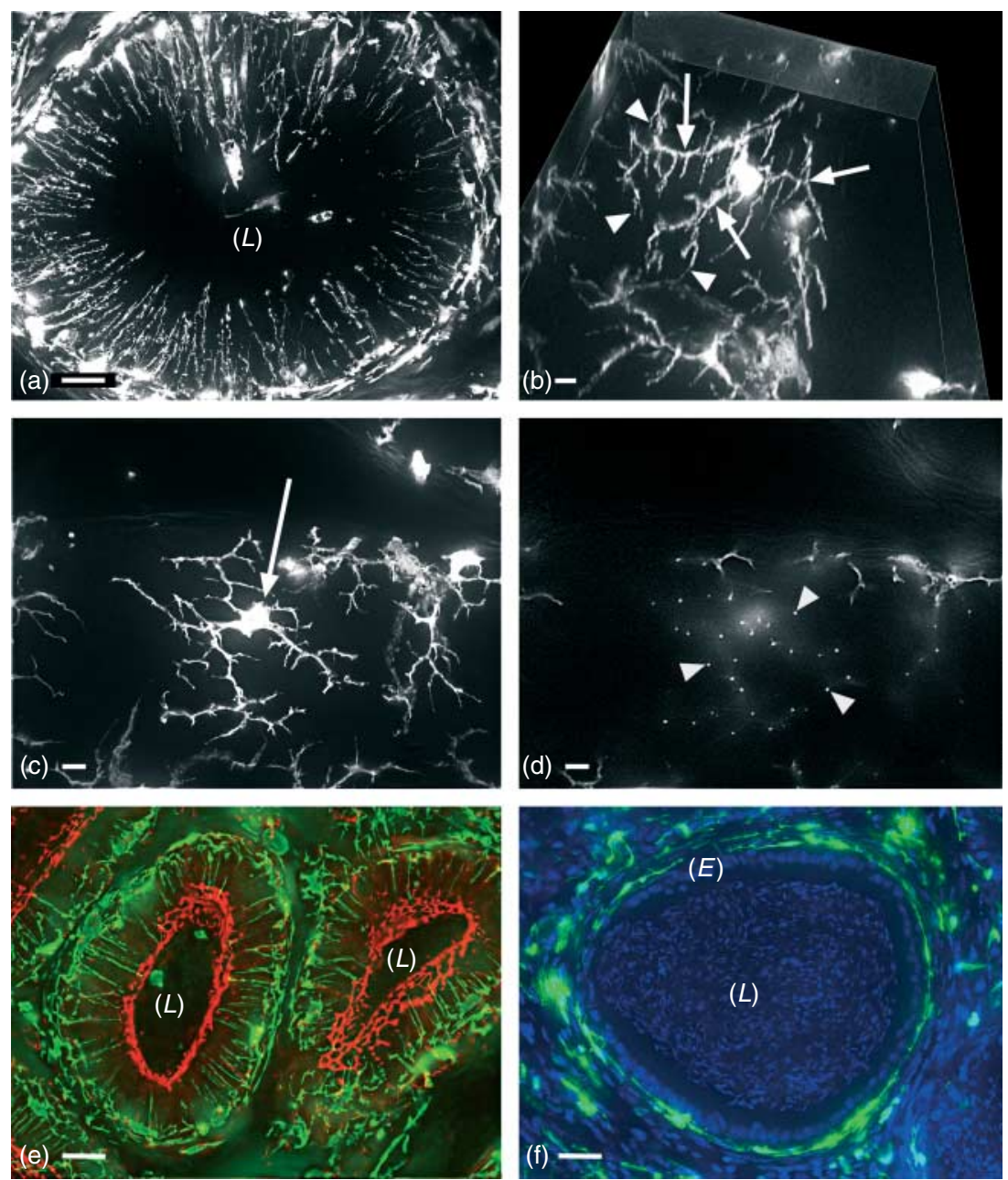

Figure 3 In the proximal epididymis, eDCs project thin processes toward the epididymal lumen. (a) Cross section of the epididymal duct of a CD11c-EYFP mouse (initial segments) showing numerous intraepithelial dendrites converging toward the lumen (L). (b) Three-dimensional view of a CD11c-EYFP ${ }^{+}$eDC, showing the bright cellular body, long lateral extensions (arrows), and slender transepithelial processes (arrowheads). (c and d) Two optical sections of epididymal CD11c-EYFP ${ }^{+}$eDCs taken at different depths. (c) The section runs through the cellular body of one DC (arrow), which has numerous lateral extensions. (d) The perpendicular intraepithelial processes appear as circular dots (arrowheads) in this section taken closer to the lumen. (e) Crosssection of the epididymal duct (initial segments) showing CX3CR1-GFP ${ }^{+}$eDCs (green) projecting processes toward the tight junctions labeled with TJP1 (red). In contrast, eDCs do not project visible intraepithelial dendrites in the epididymis tail (f). $\mathrm{E}$, epithelium. Blue $=$ DAPI. Bars $=10 \mu \mathrm{m}(\mathrm{a}-\mathrm{e})$ and $20 \mu \mathrm{m}$ (f).
Both populations of eDCs express CX3CR1 and MHC class II molecules, similar to DCs in the small intestine (Niess et al. 2005). Epididymal $\mathrm{CD}_{11 \mathrm{c}^{+}}$cells share numerous similarities with the so-called 'classical' DCs (tissue-resident steady-state DCs) described in other nonlymphoid organs such as the gut, lung, skin, and aorta (Choi et al. 2009, Helft et al. 2010). As such, CD11c ${ }^{+}$ $\mathrm{CD} 103^{+}$cells express $\mathrm{CD} 11 \mathrm{~b}$ and the co-stimulatory molecules CD40, CD80, and CD86, as well as CD1d and the macrophage marker F4/80 (Fig. 4a and b). They also express Ly6C, the C-type lectins langerin and DC-SIGN, as well as the signal regulatory protein $\alpha$, SIRP- $\alpha$, which interacts with CD47 to regulate immune homeostasis (Barclay 2009, Matozaki et al. 2009). In contrast, $\mathrm{CD}_{11 \mathrm{C}^{+}} \mathrm{CD}_{103^{-}}$eDCs express lower or undetectable levels of co-stimulatory molecules, Ly6C, DC-SIGN, langerin, F4/80, and SIRP- $\alpha$ but express CD1d, MHC class II, and, surprisingly, CD11b (Fig. 4a and b). Splenic DCs (Fig. 4b, bottom row) express lower levels of co-stimulatory molecules when compared with $\mathrm{CD} 103^{+}$ eDCs, indicating their less mature status and insignificant levels of Ly6C, F4/80, DC-SIGN, and langerin.

\section{Expression of macrophage markers in the epididymis}

DCs and macrophages belong to the notably heterogeneous MPS, and the distinction between these two cell types is still controversial (Geissmann et al. 2010). The expression of F4/80 (a macrophage marker involved in the induction of peripheral tolerance (Lin et al. 2005)) in CD11c-positive cells led us to refine the analysis of macrophage markers in the epididymis by immunofluorescence microscopy. CD11c-EYFP and the F4/80 antibody revealed three distinct populations of cells that express one marker or both (Fig. 5a-e). In addition, the mannose receptor (CD206) is expressed exclusively by a population of $\mathrm{CD} 11 \mathrm{c}$-negative cells that are located in the interstitium and are morphologically distinct from the peritubular eDCs (Fig. 5f). Higher magnification pictures clearly showed that $\mathrm{CD} 11 \mathrm{C}^{+}$ and $\mathrm{CD}_{206}{ }^{+}$cells are distinct populations (Fig. $5 \mathrm{~g}$ and $h$ ). Thus, the epididymal tubule and interstitium are populated by several subsets of mononuclear phagocytes that express a complex combination of markers traditionally described as 'dendritic cell' or 'macrophage' markers. 
A

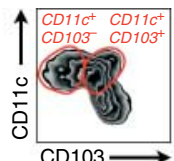

B

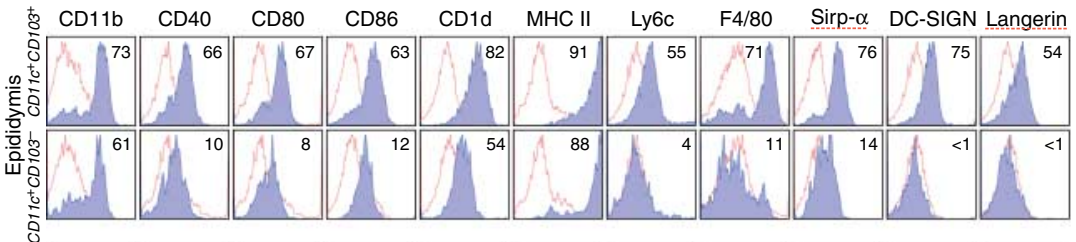

ฮั

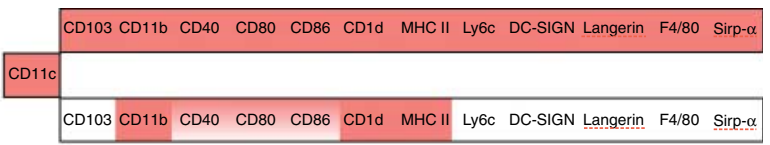

CD103 CD11b CD40 CD80 CD86 CD1d MHC II Ly6c DC-SIGN Langerin F4/80 Sirp- $\alpha$

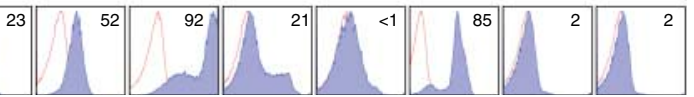

Figure 4 Flow cytometry analysis of cell surface markers in epididymal and splenic DCs isolated from C57BL/6 mice. Cell suspensions were prepared from $\mathrm{C} 57 \mathrm{BL} / 6$ mouse whole epididymis and spleen and stained with MABs to 13 markers. (a) Recapitulation of the phenotype of two major $\mathrm{CD}_{11 \mathrm{c}^{+}} \mathrm{eDC}$ populations that express or do not express CD103 (gated from the histogram shown on the left). (b) Representative histograms of the phenotype of epididymal and splenic DCs. The percentage represents the mean of at least two independent experiments. Red histograms represent isotype controls.

\section{eDCs are effective $A P C s$ in vitro}

A prerequisite for any putative role in reproductive immunophysiology is the ability of eDCs to present antigens to T cells. Therefore, we determined the antigen presentation capabilities of isolated eDCs in vitro by culturing them with chicken ovalbumin (OVA)-specific OT-I and OT-II transgenic T cells, in the presence or absence of OVA, and by assessing for T cell proliferation. In the presence of OVA, CD11 ${ }^{+} \mathrm{CD}_{11 b^{+}}$eDCs induced strong proliferation of $\mathrm{CD}^{+}(82 \%$ proliferating cells) and $\mathrm{CD} 8^{+}$(53\%) OVA-specific T cells (Fig. 6, left panels). As control, the effect of splenic DC on T cell proliferation was examined. Splenic DCs induced CD4 ${ }^{+}$ and $\mathrm{CD}^{+} \mathrm{T}$ cell proliferation by 90 and $80 \%$ respectively (Fig. 6, right panels). Thus, isolated eDCs appear to be very effective at processing and presenting antigens to $\mathrm{CD} 4{ }^{+}$and $\mathrm{CD} 8{ }^{+} \mathrm{T}$ cells in vitro.

\section{Discussion}

In order to perpetuate the species, all male amniotes have developed an epididymis, a small organ located downstream of the testis that is responsible for making gametes able to fertilize an oocyte and storing them (Da Silva et al. 2007, Cornwall 2009, Shum et al. 2009). Sperm maturation and proper storage involve
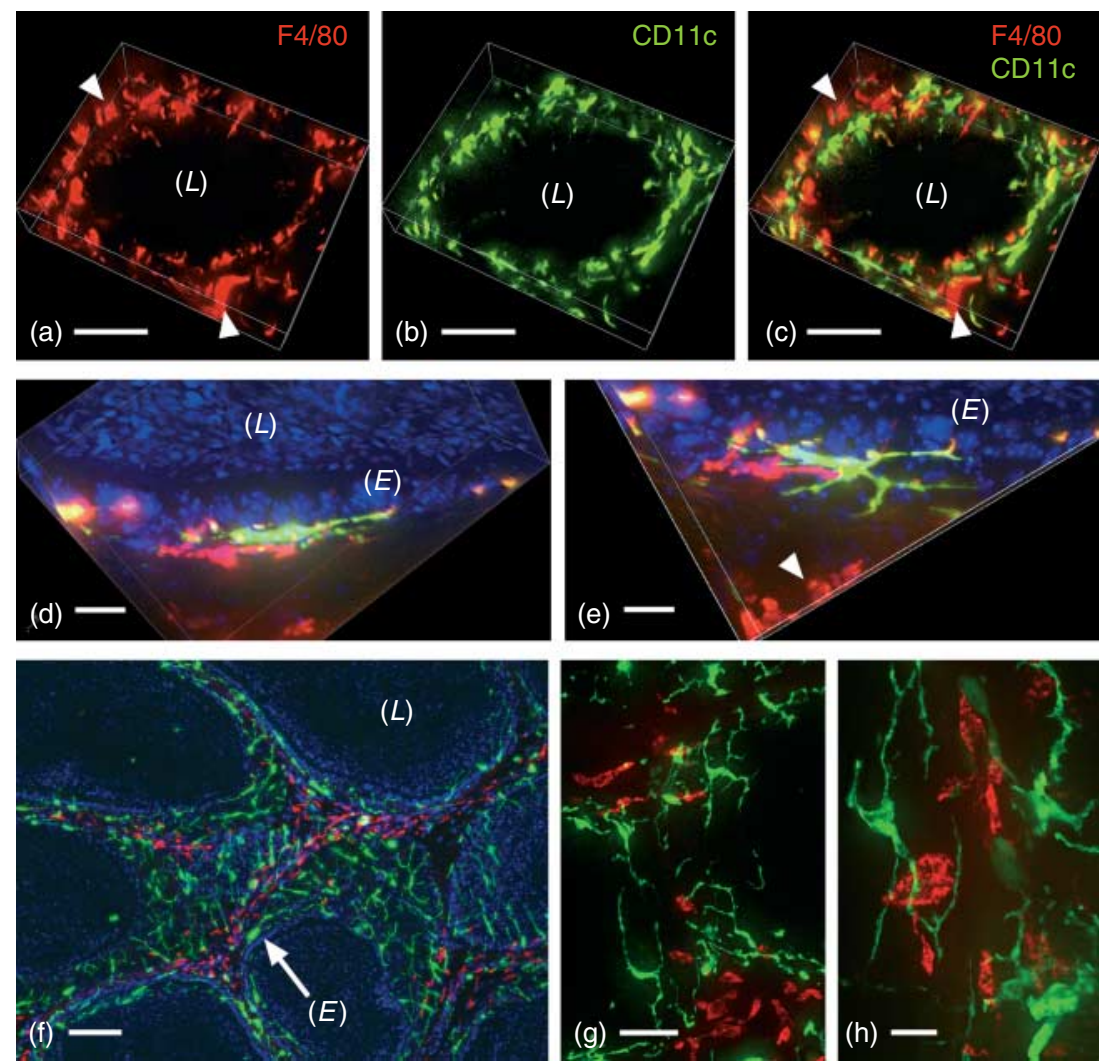

Figure 5 Expression of macrophage markers in the epididymis. F4/80 immunolabeling of CD11CEYFP mouse epididymis revealed three subsets of cells that express CD11c (green), F4/80 (red), or both markers (yellow). CD11 ${ }^{-} \mathrm{F} 4 / 80^{+}$cells (a, c, e, arrowheads) tend to be more interstitial than $\mathrm{CD} 11 \mathrm{C}^{+} \mathrm{F} 4 / 80^{-}$cells. However, highmagnification pictures $d$ and e show that cells positive for both markers are also present in the peritubular region. $(\mathrm{f}-\mathrm{h})$ : the macrophage marker CD206 (mannose receptor) is expressed exclusively by interstitial cells. Sections of CD11c-EYFP (green) mouse epididymis were immunolabeled with an anti-CD206 antibody (red). Although $\mathrm{CD} 11 \mathrm{c}^{+}$cells are located mostly in the peritubular region, the $\mathrm{CD}_{20} 6^{+}$macrophages are exclusively interstitial. Higher magnification $(h)$ reveals the non-stellate morphology of interstitial CD206 ${ }^{+}$cells, contrasting with eDCs (green). DNA staining (in d, e and $f$, blue) helps to appreciate the structure of the tissue, with rows of nuclei from epithelial cells (E) and luminal nuclei from spermatozoa. Bars $=50$ $(\mathrm{a}-\mathrm{C}, \mathrm{f}), 25(\mathrm{~g})$, and $10 \mu \mathrm{m}(\mathrm{d}, \mathrm{e}, \mathrm{h}) . \mathrm{L}$, lumen. 


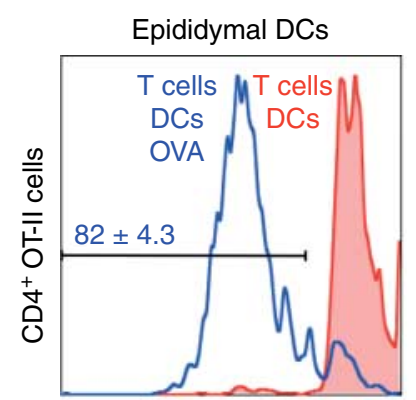

CFSE

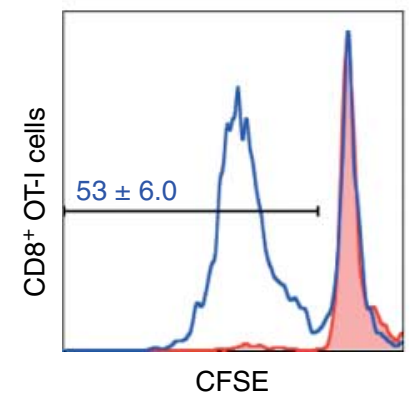

Figure 6 In vitro antigen presentation to T cells by epididymal and splenic DCs. CD $11 b^{+}$CD11 ${ }^{+}$DCs were isolated from C57BL/6 epididymis and spleen by FACS, as well as $\mathrm{CD} 4{ }^{+} \mathrm{OT}-\mathrm{Il}$ and $\mathrm{CD} 8{ }^{+} \mathrm{OT}-\mathrm{I}$ T cells. DCs and CFSE-labeled T cells were co-cultured for 5 days in the presence (blue) or absence (red) of OVA protein. Proliferation of T cells was assessed by flow cytometry. The percentage of proliferating cells is indicated in blue. Histograms are representative of two independent experiments.

complex mechanisms, which are regulated by the pseudostratified epithelium that lines the entire excurrent ductal system and is under the control of the endocrine system (Ezer \& Robaire 2002, Hess et al. 2002, Robaire et al. 2007, Cornwall 2009, Shum et al. 2009). Surprisingly, one of the most understudied aspects of epididymal physiology is its interaction with the immune system (Hedger \& Hales 2006). The epididymal mucosal system must protect autoantigen-coated spermatozoa from destruction by the immune system as well as invading pathogens. DCs, the specialized APCs that are key regulators of immune responses in numerous organs (Banchereau \& Steinman 1998, Steinman et al. 2003, Steinman \& Banchereau 2007, Helft et al. 2010), had been thought to be absent from the epididymal epithelium in order to prevent immune activation (Seiler et al. 2000). However, we describe in this study an extensive network of DCs and macrophages that populate the entire organ and seem to be strategically positioned to actively regulate the interactions between the reproductive and the immune systems. Two transgenic mouse models, which have been widely used to characterize DCs in numerous organs, revealed the presence of $\mathrm{CD} 11 \mathrm{c}^{+}$and CX3CR $1^{+}$cells that establish close contact with the epididymal epithelium.

The mouse epididymis is a continuous but segmented organ that has at least two clearly distinct functions: spermatozoa mature mostly in the most proximal segments (head), although the distal regions (body and tail) are also sites of storage. Although all epididymal DCs express the markers CD11C and CX3CR1, we show in this study that intraepithelial dendrites are particularly abundant in the initial segments. These cells resemble the $\mathrm{F} 4 / 80^{+}$cells observed by Mullen et al. (2003) although all the epididymal leukocytes described by this group were CD11b-negative. In the initial segments, most, if not all, epithelial cells seem to be in direct contact with an eDC, and we determined that each eDC extends dozens of intraepithelial dendrites toward the tight junctions that constitute the so-called bloodepididymis barrier. This portion of the tubule is the first segment encountered by spermatozoa after their short transit in the efferent ducts. The initial segments are, therefore, likely to play a primary role in the acceptance of maturing sperm cells by the immune system. Interestingly, the initial segments are also the most vascularized region of the epididymis (Suzuki 1982, Abe et al. 1984) and, consequently, the most readily accessible region for blood-borne differentiated cells and/or progenitors. In addition, the lumen in these segments is relatively narrow (its diameter represents about one-tenth of the tubular diameter in the distal epididymis tail), which increases the probability of direct interactions between spermatozoa, epithelial cells, and any cell type capable of projecting intraluminal extensions such as basal cells (Shum et al. 2008) and, possibly, DCs (Niess et al. 2005) and other leukocytes (Mullen et al. 2003). Finally, the initial segments are the region of the epididymis that is least likely to be infected by ascending pathogens. It has been suggested that the CX3CR1-expressing intestinal DCs with transepithelial sampling capabilities are essentially macrophages involved in maintaining the mucosa rather than initiating T cell responses (Geissmann et al. 2010). If scavenging activity is necessary in the male excurrent duct, it should occur all along the epididymal duct and particularly in the distal region, which is the site where sperm are stored for a long period of time (several days to several weeks). Thus, we believe that intraepithelial dendrites are present in the initial segments because it is the region where they are the most likely to interact with sperm and/or luminal components released by spermatozoa very early in the post-testicular maturation process. In doing so, eDCs could be involved in the establishment and maintenance of immune tolerance to maturating spermatozoa that express new autoantigens, which is a critical step in the establishment of male fertility. In contrast, the exclusively peritubular DCs observed in the steady-state cauda epididymis might be 'sentinels' that regulate, when necessary, inflammation and immune responses against ascending pathogens. eDCs could complement the action of testicular DCs, which have been detected in the normal and inflamed testis but are, by definition, never in contact with fully mature 
spermatozoa (Fijak \& Meinhardt 2006, Rival et al. 2006, 2007, Guazzone et al. 2011).

We characterized distinct populations of $\mathrm{CD} 11 \mathrm{c}^{+}$ $\mathrm{CD}_{103}{ }^{+}$and $\mathrm{CD} 11 \mathrm{c}^{+} \mathrm{CD}_{103}{ }^{-}$DCs in the epididymis. In this respect, eDCs resemble resident DCs described in other non-lymphoid tissues such as the skin, liver, kidney, and intestine (Helft et al. 2010). CD103 ${ }^{+}$DCs exhibit tolerogenic properties in the gut (Coombes et al. 2007, Coombes \& Powrie 2008, Matteoli et al. 2010) and they are also functionally specialized in the skin and in the lung (Ginhoux et al. 2009). Although the epididymis and the gut are functionally unrelated, the DCs that populate their mucosae may have to face similar challenges. Epididymal and intestinal mucosa survey a luminal environment in which they have to make the distinction between pathogens and hundred of millions of spermatozoa, or pathogens, and the very abundant and heterogeneous commensal flora respectively (Niess \& Reinecker 2005, 2006). In both organs, the 'sentinels' of the immune system must sample the luminal environment without disrupting the barrier function of the epithelium. Any alteration of the fragile balance between tolerance and immunogenicity has the potential to trigger autoimmune or inflammatory disorders such as autoimmune infertility in the testis and the epididymis and inflammatory bowel disease in the gastrointestinal tract (Niess \& Reinecker 2005, 2006). Peripheral tolerance involves complex mechanisms aiming at selecting negatively autoreactive $\mathrm{T}$ cells, controlling locally the $\mathrm{T}$ cells that escape thymic selection and separating these cells from the autoantigens (Mueller 2010). The density of the eDC network described in this study is such that low-avidity T cells that express self-peptide MHC are likely to react, causing a failure of peripheral tolerance and, ultimately, autoimmune infertility. In the gut, a population of CD11 $\mathrm{C}^{+}$ $\mathrm{CD} 103^{+}$DCs exhibit tolerogenic (Steinman et al. 2003) properties via indoleamine 2,3-dioxygenase (IDO)dependent mechanisms and play, therefore, a critical role in the establishment of oral tolerance to food antigens (Iliev et al. 2009, Matteoli et al. 2010). Interestingly, IDO is abundantly expressed in the epididymis (Britan et al. 2006, Drevet 2006, Jrad-Lamine et al. 2011), but its potential roles in adaptive immunity in this organ remain to be elucidated.

The microscopic analysis of three markers $(C D 11 \mathrm{c}$, F4/80 and CD206/mannose receptor) revealed the presence of at least four distinguishable cell types in the epididymis. CD206-positive cells do not express CD11c, they are exclusively interstitial and do not exhibit the stellate morphology of $\mathrm{CD}_{11 \mathrm{c}^{+}}$cells. F4/80 is expressed by a subset of $\mathrm{CD} 11 \mathrm{c}^{+}$cells as well as some CD $11 \mathrm{c}^{-}$cells. In fact, flow cytometry and microscopic analyses are snapshots that are not sufficient to reveal the dynamics and phenotypical modulation of DCs and macrophages. In the absence of inflammation, the epididymis is heavily populated by the 'infamously heterogeneous' (Geissmann et al. 2010) MPS and this heterogeneity might reflect, at least in part, the dual function of this organ. The maturation, storage, and perhaps selection (Sutovsky et al. 2001, Cooper et al. 2002) processes that occur in the epididymis are likely to involve phenotypically and functionally distinct subsets of cells with antigen-presenting capabilities, including 'immunogenic' and 'tolerogenic' DCs. A region-specific characterization of eDCs will help to better understand the heterogeneity observed in the whole organ. Interestingly, the $\mathrm{CD} 103^{+} \mathrm{eDCs}$ expressed relatively high levels of DC-SIGN (CD209) and langerin (CD207). These markers, which are C-type lectins that bind mannosecontaining glycoproteins, are involved in infection by viruses such as HIV (de Witte et al. 2007, 2008). The role of DC-SIGN- and langerin-positive eDCs during HIV infection should be further investigated, as the epididymis is a major target and reservoir of HIV (Mullen et al. 2003, Shehu-Xhilaga et al. 2007).

In accordance with their high level of expression of MHC and co-stimulatory molecules, we show that isolated $\mathrm{CD}_{11 \mathrm{c}^{+}}$eDCs have strong antigen-presenting and cross-presenting capabilities in vitro. The antigenpresenting capabilities of eDCs, as well as their migratory properties, should be established in vivo in future studies. However, the results described here leave little doubt that the abundant eDCs play a critical immunological role in the male excurrent duct, in close relationship with epithelial cells, which may regulate the delivery of antigens to peritubular DCs as well as the dynamics of DC processes as they extend towards the lumen (possibly via a CX3CR1-dependent mechanism). In addition, we cannot exclude complementary direct antigen-presenting capabilities of epithelial cells during inflammation, as was described in the gut (Shale \& Ghosh 2009). The influence of sex hormones on eDC distribution and function should also be investigated. Indeed, female sex steroids directly regulate the function of DCs (Hughes \& Clark 2007) and, surprisingly, estrogens are abundant in the epididymis (Hess et al. 2002). Finally, the abundance of DCs in the epididymis in the absence of infection/inflammation also raises the possibility of additional and non-immune roles for these cells. In the steady-state brain, $\mathrm{CD}_{11 \mathrm{C}^{+}} \mathrm{DCs}$ are particularly abundant in the regions where the bloodbrain barrier is weak or absent, and a possible role of DCs in neurogenesis and regulation of $\mathrm{CN}$ plasticity was suggested (Bulloch et al. 2008). Similarly, eDCs could be actively involved in the maintenance of the complex epididymal epithelium. In contrast with immunologically privileged sites such as the anterior chamber of the eye (Streilein 1993, Stein-Streilein 2008) and the brain, which are partially isolated from the immune system by a deficient lymphatic drainage, the epididymis contains abundant lymphatic channels (Kazeem 1983, 1988). Therefore, immunological information gathered by eDCs could be processed in local lymph nodes to 
generate regulatory $\mathrm{T}$ cells and effector $\mathrm{T}$ cells. The functions of DCs and other APCs in reproductive biology have been studied mostly in the female genital tract and in the testis (Bizargity \& Bonney 2009, Guazzone et al. 2011, Ivanisevic et al. 2010). Their role in the post-testicular environment must be unraveled, and studying the cellular mechanisms of mucosal immunity in the epididymis will require massive efforts aiming at adapting intravital imaging and in vivo antigen stimulation protocols to this small but relatively accessible organ.

\section{Materials and Methods}

\section{Mice}

CD11c-EYFP mice (Lindquist et al. 2004) were a gift from the laboratory of M C Nussenzweig (The Rockefeller University, New York, NY, USA). CX3CR1-GFP mice (Jung et al. 2000) were a gift from D R Littman (Skirball Institute, New York, NY, USA). The mice referred as 'CX3CR1-GFP' in this study are exclusively $\mathrm{C} \times 3 \mathrm{Cr}^{\mathrm{gfp} /+}$ mice, obtained by breeding $\mathrm{C} \times 3 \mathrm{cr} 1^{\mathrm{g}}{ }^{\mathrm{fp} /}$ gfp males with wild-type females (C57BL/6; The Jackson Laboratory, Bar Harbor, ME, USA). Transgenic and wild-type mice were maintained free of common rodent pathogens and on a standard diet. Mouse protocols were approved by the Massachusetts General Hospital Institutional Animal Care and Use Committee.

\section{$\mathrm{eDC}$ isolation}

For eDC isolation, we modified a protocol used previously to prepare epididymal single-cell suspensions (Da Silva et al. 2010). Briefly, epididymides were dissected and cut into small pieces with scissors in dissociation medium (RPMI 1640 with $0.5 \mathrm{mg} / \mathrm{ml}$ collagenase type I and $0.5 \mathrm{mg} / \mathrm{ml}$ collagenase type II, $1 \mathrm{ml}$ per epididymis pair). Tissues were incubated for $30 \mathrm{~min}$ at $37^{\circ} \mathrm{C}$ with gentle shaking. After enzymatic digestion, cells were passed through a $70 \mu \mathrm{m}$ nylon mesh strainer, washed in PBS with $1 \%$ BSA, and stored on ice until processing.

\section{Antibodies, negative selection of eDCs, and flow cytometry}

For negative selection of eDCs, cell suspensions were incubated with a cocktail of MABs against T cells (CD90-PE, 53-2.1), B cells (B220-PE, RA3-6B2), natural killer cells (CD49b-PE, DX5 and NK1.1-PE, PK136), and granulocytes (Ly-6G-PE, 1A8). After washing, the cells were incubated with anti-PE microbeads as indicated by the manufacturer's protocol (Miltenyi Biotec, Auburn, CA, USA) and pass thereafter through a MACS LD column. eDCs were then labeled with CD11c-FITC (HL3), CD11c-Alexa 700 (HL3), CD11b-APC-Cy7 (M1/70), Ly-6C-biotin (AL-21), MHC class II-APC (M5/114.15.2), CD86-PE (GL1), CD1d-biotin (CD1.1, Ly-38), CD40-APC (3/23), DC-SIGN-biotin (5H10), CD80-APC (16-10A1), langerin-biotin (eBioL31), SIRP- $\alpha$-FITC (P84), and CD206biotin. Antibodies were purchased from BD Biosciences (San Jose, CA, USA) or eBioscience (San Diego, CA, USA).
Data were acquired on an LSRII flow cytometer (BD Biosciences) and analyzed with Flowjo 8 or 9 (Tree Star, Ashland, OR, USA). For in vitro proliferation assays, DCs and T cells were sorted on a BD FACSAria (BD Biosciences) based on CD11b and CD11c expression.

\section{Immunofluorescence and microscopy analyses}

Mice were anesthetized with nembutal $(50 \mathrm{mg} / \mathrm{kg}$, i.p.). Epididymides were fixed by perfusion through the left ventricle with periodate-lysine-paraformaldehyde (PLP) fixative, as we have described previously (Da Silva et al. 2006), or PBS with $4 \%$ paraformaldehyde. Cryoprotected tissues were sectioned $(10-50 \mu \mathrm{m})$ in a cryostat. Immunolabeling was performed as described previously (Da Silva et al. 2006) with the following antibodies: TJP1 (R40.76, kindly provided by Dr Eveline Schneeberger), CD206 (MR5D3, AbD Serotec, Raleigh, NC, USA), Cy3 goat anti-rat IgG (Invitrogen), and DyLight 649 goat anti-rat IgG (Jackson ImmunoResearch, West Grove, PA, USA). F4/80 labeling was performed using the tyramide signal amplification system (Perkin Elmer, Waltham, MA, USA), anti-F4/80 IgG (BM8, eBioscience), and a HRPcoupled donkey anti-rat IgG (Jackson ImmunoResearch). Microscopic images were acquired using Eclipse 80i and 90i epifluorescence microscopes (Nikon Instruments, Melville, NY, USA), a Radiance 2000 confocal microscope (Carl Zeiss, Thornwood, NY, USA and Bio-Rad), and an Olympus FV1000 multiphoton microscope. Digital images were processed with IPLab (Scanalytics, Fairfax, VA, USA), NIS Elements (Nikon Instruments), Volocity 5 (Perkin Elmer), ImageJ, or Matlab (MathWorks, Natick, MA, USA).

\section{In vitro OVA presentation}

Single-cell suspensions pooled from mesenteric lymph nodes and spleen of OT-I and OT-II C57BL/6 mice were flow sorted for the isolation of $\mathrm{CD}^{+}$and $\mathrm{CD}^{+}{ }^{+} \mathrm{T}$ cells obtaining a purity $>98 \%$ for each $\mathrm{T}$ cell population. Purified $\mathrm{T}$ cells were labeled with carboxyfluorescein succinimidyl ester (CFSE, $5 \mu \mathrm{M}$ ) and then stimulated in vitro in complete medium (RPMI medium 1640 with sodium $1 \mathrm{mM}$ pyruvate, $10 \mathrm{mM}$ HEPES, $2 \mathrm{mM}$ glutamine, $1 \%$ penicillin-streptomycin, $50 \mu \mathrm{M}$ mercaptoethanol, and 10\% heat-inactivated FCS) for 5 days in the presence or absence of eDCs (4-5:1 ratio respectively) and $/$ or $200 \mu \mathrm{g} / \mathrm{ml}$ OVA (Sigma-Aldrich) and maintained at $37^{\circ} \mathrm{C}$. Cells were harvested and proliferation was measured based on CFSE dilution by flow cytometry.

\section{Supplementary data}

This is linked to the online version of the paper at http://dx.doi. org/10.1530/REP-10-0493.

\section{Declaration of interest}

The authors declare that there is no conflict of interest that could be perceived as prejudicing the impartiality of the research reported. 


\section{Funding}

This study was supported by National Institutes of Health grants DK085715 and DK38452 (S Breton), MGH Center for the Study of Inflammatory Bowel Disease (CSIBD) pilot feasibility grant (DK43351, N Da Silva), CA086355 and AI084880 (M J Pittet), R01HL095612 (F K Swirski). The Microscopy Core facility of the MGH Program in Membrane Biology receives support from the Boston Area Diabetes and Endocrinology Research Center (DK57521) and the CSIBD (DK43351).

\section{Acknowledgements}

We thank Michael Waring (Ragon Institute Flow Cytometry Facility) for FACS sorting, Claudio Vinegoni for some image acquisition and processing, and Dr Siamon Gordon for his kind advice.

\section{References}

Abe K, Takano H \& Ito T 1984 Microvasculature of the mouse epididymis, with special reference to fenestrated capillaries localized in the initial segment. Anatomical Record 209 209-218. (doi:10.1002/ar. 1092090208)

Banchereau J \& Steinman RM 1998 Dendritic cells and the control of immunity. Nature 392 245-252. (doi:10.1038/32588)

Barclay AN 2009 Signal regulatory protein $\alpha(\mathrm{SIRP} \alpha) / \mathrm{CD} 47$ interaction and function. Current Opinion in Immunology 21 47-52. (doi:10.1016/j.coi. 2009.01.008)

Barratt CL, Bolton AE \& Cooke ID 1990 Functional significance of white blood cells in the male and female reproductive tract. Human Reproduction 5 639-648.

Bizargity P \& Bonney EA 2009 Dendritic cells: a family portrait at midgestation. Immunology 126 565-578. (doi:10.1111/j.1365-2567.2008. 02918.x)

Britan A, Maffre V, Tone S \& Drevet JR 2006 Quantitative and spatial differences in the expression of tryptophan-metabolizing enzymes in mouse epididymis. Cell and Tissue Research 324 301-310. (doi:10. 1007/s00441-005-0151-7)

Bulloch K, Miller MM, Gal-Toth J, Milner TA, Gottfried-Blackmore A Waters EM, Kaunzner UW, Liu K, Lindquist R, Nussenzweig MC et al. 2008 CD11c/EYFP transgene illuminates a discrete network of dendritic cells within the embryonic, neonatal, adult, and injured mouse brain Journal of Comparative Neurology 508 687-710. (doi:10.1002/cne. 21668)

Chan PTK \& Schlegel PN 2002 Epididymitis and other conditions of the male excurrent ductal system. In The Epididymis: From Molecules to Clinical Practice: A Comprehensive Survey of Efferent Ducts, The Epididymis and the Vas Deferens, 1st edn, pp 533-553. New York: Springer.

Choi JH, Do Y, Cheong C, Koh H, Boscardin SB, Oh YS, Bozzacco L, Trumpfheller C, Park CG \& Steinman RM 2009 Identification of antigenpresenting dendritic cells in mouse aorta and cardiac valves. Journal of Experimental Medicine 206 497-505. (doi:10.1084/jem.20082129)

Coombes JL \& Powrie F 2008 Dendritic cells in intestinal immune regulation. Nature Reviews. Immunology 8 435-446. (doi:10.1038/ nri2335)

Coombes JL, Siddiqui KR, Arancibia-Carcamo CV, Hall J, Sun CM, Belkaid Y \& Powrie F 2007 A functionally specialized population of mucosal $\mathrm{CD}_{103}{ }^{+}$DCs induces Foxp ${ }^{+}$regulatory T cells via a TGF- $\beta$ and retinoic acid-dependent mechanism. Journal of Experimental Medicine 204 1757-1764. (doi:10.1084/jem.20070590)

Cooper TG, Yeung CH, Jones R, Orgebin-Crist MC \& Robaire B 2002 Rebuttal of a role for the epididymis in sperm quality control by phagocytosis of defective sperm. Journal of Cell Science 115 5-7.

Cornwall GA 2009 New insights into epididymal biology and function. Human Reproduction Update 15 213-227. (doi:10.1093/humupd/ dmn055)
Cunningham KA \& Beagley KW 2008 Male genital tract chlamydial infection: implications for pathology and infertility. Biology of Reproduction 79 180-189. (doi:10.1095/biolreprod.108.067835)

Da Silva N, Silberstein C, Beaulieu V, Pietrement C, Van Hoek AN, Brown D \& Breton S 2006 Postnatal expression of aquaporins in epithelial cells of the rat epididymis. Biology of Reproduction $\mathbf{7 4}$ 427-438. (doi:10.1095/biolreprod.105.044735)

Da Silva N, Shum WW \& Breton S 2007 Regulation of vacuolar proton pumping ATPase-dependent luminal acidification in the epididymis. Asian Journal of Andrology 9 476-482. (doi:10.1111/j.1745-7262.2007.00299.x)

Da Silva N, Pisitkun T, Belleannee C, Miller LR, Nelson RD, Knepper MA, Brown D \& Breton S 2010 Proteomic analysis of V-ATPase-rich cells harvested from the kidney and epididymis by fluorescence activated cell sorting. American Journal of Physiology. Cell Physiology 298 C1326-C1342. (doi:10.1152/ajpcell.00552.2009)

Drevet JR 2006 The antioxidant glutathione peroxidase family and spermatozoa: a complex story. Molecular and Cellular Endocrinology 250 70-79. (doi:10.1016/j.mce.2005.12.027)

Ezer N \& Robaire B 2002 Androgenic regulation of the structure and function of the epididymis. In The Epididymis: From Molecules to Clinical Practice: A Comprehensive Survey of Efferent Ducts, The Epididymis and the Vas Deferens, 1st edn, pp 297-316. New York: Springer.

Fijak M \& Meinhardt A 2006 The testis in immune privilege. Immunological Reviews 213 66-81. (doi:10.1111/j.1600-065X.2006.00438.x)

Flickinger CJ, Bush LA, Howards SS \& Herr JC 1997 Distribution of leukocytes in the epithelium and interstitium of four regions of the Lewis rat epididymis. Anatomical Record 248 380-390. (doi:10.1002/ (SICI)1097-0185(199707)248:3 <380::AID-AR11>3.0.CO;2-L)

Geissmann F, Gordon S, Hume DA, Mowat AM \& Randolph GJ 2010 Unravelling mononuclear phagocyte heterogeneity. Nature Reviews. Immunology 10 453-460. (doi:10.1038/nri2784)

Ginhoux F, Liu K, Helft J, Bogunovic M, Greter M, Hashimoto D, Price J, Yin N, Bromberg J, Lira SA et al. 2009 The origin and development of nonlymphoid tissue $\mathrm{CD}_{103^{+}}$DCs. Journal of Experimental Medicine 206 3115-3130. (doi:10.1084/jem.20091756)

Guazzone VA, Hollwegs S, Mardirosian $M$, Jacobo $\mathbf{P}$, Hackstein $\mathbf{H}$, Wygrecka M, Schneider E, Meinhardt A, Lustig L \& Fijak M 2011 Characterization of dendritic cells in testicular draining lymph nodes in a rat model of experimental autoimmune orchitis. International Journal of Andrology [in press]. (doi:10.1111/j.1365-2605.2010.01082.x)

Hedger MP \& Hales DB 2006 Immunophysiology of the male reproductive tract. In Knobil and Neill's Physiology of Reproduction, 3rd edn, pp 1195-1286. St Louis: Elsevier Academic Press.

Helft J, Ginhoux F, Bogunovic M \& Merad M 2010 Origin and functional heterogeneity of non-lymphoid tissue dendritic cells in mice. Immunological Reviews 234 55-75. (doi:10.1111/j.0105-2896. 2009.00885.x)

Hess RA, Zhou Q \& Nie R 2002 The role of estrogens in the endocrine ad paracrine regulation of the efferent ductules, epididymis and vas deferens. In The Epididymis: From Molecules to Clinical Practice: A Comprehensive Survey of Efferent Ducts, The Epididymis and the Vas Deferens, 1st edn, pp 317-337. New York: Springer.

Hooper P, Smythe E, Richards RC, Howard CV, Lynch RV \& Lewis-Jones DI 1995 Total number of immunocompetent cells in the normal rat epididymis and after vasectomy. Journal of Reproduction and Fertility 104 193-198. (doi:10.1530/jrf.0.1040193)

Hughes GC \& Clark EA 2007 Regulation of dendritic cells by female sex steroids: relevance to immunity and autoimmunity. Autoimmunity $\mathbf{4 0}$ 470-481. (doi:10.1080/08916930701464764)

Iliev ID, Spadoni I, Mileti E, Matteoli G, Sonzogni A, Sampietro GM, Foschi D, Caprioli F, Viale G \& Rescigno M 2009 Human intestinal epithelial cells promote the differentiation of tolerogenic dendritic cells. Gut 58 1481-1489. (doi:10.1136/gut.2008.175166)

Ivanisevic M, Segerer S, Rieger L, Kapp M, Dietl J, Kammerer U \& Frambach T 2010 Antigen-presenting cells in pregnant and non-pregnant human myometrium. American Journal of Reproductive Immunology 64 188-196. (doi:10.1111/j.1600-0897.2010.00858.x)

Jrad-Lamine A, Henry-Berger J, Gourbeyre P, Damon-Soubeyrand C, Lenoir A, Combaret L, Saez F, Kocer A, Tone S, Fuchs D et al. 2011 Deficient-tryptophan catabolism along the kynurenine pathway reveals that the epididymis is in a unique tolerogenic state. Journal of Biological Chemistry 286 8030-8042. (doi:10.1074/jbc.M110.172114) 
Jung S, Aliberti J, Graemmel P, Sunshine MJ, Kreutzberg GW, Sher A \& Littman DR 2000 Analysis of fractalkine receptor CX(3)CR1 function by targeted deletion and green fluorescent protein reporter gene insertion. Molecular and Cellular Biology 20 4106-4114. (doi:10.1128/MCB.20. 11.4106-4114.2000)

Kazeem AA 1983 The assessment of epididymal lymphatics within the concept of immunologically privileged sites. Lymphology 16 168-171.

Kazeem AA 1988 A critical consideration of the rat epididymis as an immunologically privileged site. Scandinavian Journal of Immunology 27 149-156. (doi:10.1111/j.1365-3083.1988.tb02333.x)

Levy S \& Robaire B 1999 Segment-specific changes with age in the expression of junctional proteins and the permeability of the bloodepididymis barrier in rats. Biology of Reproduction 60 1392-1401. (doi:10.1095/biolreprod60.6.1392)

Lin $\mathbf{H H}$, Faunce DE, Stacey $M$, Terajewicz A, Nakamura T, ZhangHoover J, Kerley M, Mucenski ML, Gordon S \& Stein-Streilein J 2005 The macrophage F4/80 receptor is required for the induction of antigen-specific efferent regulatory $\mathrm{T}$ cells in peripheral tolerance. Journal of Experimental Medicine 201 1615-1625. (doi:10.1084/jem. 20042307)

Lindquist RL, Shakhar G, Dudziak D, Wardemann H, Eisenreich T, Dustin ML \& Nussenzweig MC 2004 Visualizing dendritic cell networks in vivo. Nature Immunology 5 1243-1250. (doi:10.1038/ni1139)

Matozaki T, Murata Y, Okazawa H \& Ohnishi H 2009 Functions and molecular mechanisms of the CD47-SIRP $\alpha$ signalling pathway. Trends in Cell Biology 19 72-80. (doi:10.1016/j.tcb.2008.12.001)

Matteoli G, Mazzini E, Iliev ID, Mileti E, Fallarino F, Puccetti P, Chieppa M \& Rescigno M 2010 Gut CD103 ${ }^{+}$dendritic cells express indoleamine 2,3-dioxygenase which influences $T$ regulatory/T effector cell balance and oral tolerance induction. Gut 59 595-604. (doi:10.1136/gut.2009. 185108)

McLachlan RI 2002 Basis, diagnosis and treatment of immunological infertility in men. Journal of Reproductive Immunology 57 35-45. (doi:10.1016/S0165-0378(02)00014-1)

Meinhardt A \& Hedger MP 2010 Immunological, paracrine and endocrine aspects of testicular immune privilege. Molecular and Cellular Endocrinology 335 60-68. (doi:10.1016/j.mce.2010.03.022)

Miloud T, Hammerling GJ \& Garbi N 2010 Review of murine dendritic cells: types, location, and development. Methods in Molecular Biology 595 21-42. (doi:10.1007/978-1-60761-421-0_2)

Mueller DL 2010 Mechanisms maintaining peripheral tolerance. Nature Immunology 11 21-27. (doi:10.1038/ni.1817)

Mullen TE Jr, Kiessling RL \& Kiessling AA 2003 Tissue-specific populations of leukocytes in semen-producing organs of the normal, hemicastrated, and vasectomized mouse. AIDS Research and Human Retroviruses 19 235-243. (doi:10.1089/088922203763315740)

Nashan D, Malorny U, Sorg C, Cooper T \& Nieschlag E 1989 Immunocompetent cells in the murine epididymis. International Journal of Andrology 12 85-94. (doi:10.1111/j.1365-2605.1989.tb01289.x)

Nashan D, Cooper TG, Knuth UA, Schubeus P, Sorg C \& Nieschlag E 1990 Presence and distribution of leucocyte subsets in the murine epididymis after vasectomy. International Journal of Andrology 13 39-49. (doi:10. 1111/j.1365-2605.1990.tb00958.x)

Nashan D, Jantos C, Ahlers D, Bergmann M, Schiefer HG, Sorg C \& Nieschlag E 1993 Immuno-competent cells in the murine epididymis following infection with Escherichia coli. International Journal of Andrology 16 47-52. (doi:10.1111/j.1365-2605.1993.tb01152.x)

Niess JH \& Reinecker HC 2005 Lamina propria dendritic cells in the physiology and pathology of the gastrointestinal tract. Current Opinion in Gastroenterology 21 687-691. (doi:10.1097/01.mog.0000181710. 96904.58)

Niess JH \& Reinecker HC 2006 Dendritic cells: the commanders-in-chief of mucosal immune defenses. Current Opinion in Gastroenterology 22 354-360. (doi:10.1097/01.mog.0000231807.03149.54)

Niess JH, Brand S, Gu X, Landsman L, Jung S, McCormick BA, Vyas JM, Boes M, Ploegh HL, Fox JG et al. 2005 CX3CR1-mediated dendritic cell access to the intestinal lumen and bacterial clearance. Science $\mathbf{3 0 7}$ 254-258. (doi:10.1126/science.1102901)

Pattinson HA \& Mortimer D 1987 Prevalence of sperm surface antibodies in the male partners of infertile couples as determined by immunobead screening. Fertility and Sterility $\mathbf{4 8}$ 466-469.
Pelletier RM 1994 Blood barriers of the epididymis and vas deferens act asynchronously with the blood barrier of the testis in the mink (Mustela vison). Microscopy Research and Technique 27 333-349. (doi:10.1002/ jemt.1070270408)

Pollanen P \& Cooper TG 1994 Immunology of the testicular excurrent ducts. Journal of Reproductive Immunology 26 167-216. (doi:10.1016/ 0165-0378(94)90019-1)

Ritchie AW, Hargreave TB, James K \& Chisholm GD 1984 Intra-epithelial lymphocytes in the normal epididymis. A mechanism for tolerance to sperm auto-antigens? British Journal of Urology 56 79-83. (doi:10.1111/ j.1464-410X.1984.tb07169.x)

Rival C, Lustig L, losub R, Guazzone VA, Schneider E, Meinhardt A \& Fijak M 2006 Identification of a dendritic cell population in normal testis and in chronically inflamed testis of rats with autoimmune orchitis. Cell and Tissue Research 324 311-318. (doi:10.1007/s00441-005-0129-5)

Rival C, Guazzone VA, von Wulffen W, Hackstein H, Schneider E, Lustig L, Meinhardt A \& Fijak M 2007 Expression of co-stimulatory molecules, chemokine receptors and proinflammatory cytokines in dendritic cells from normal and chronically inflamed rat testis. Molecular Human Reproduction 13 853-861. (doi:10.1093/molehr/gam067)

Robaire B, Seenundun S, Hamzeh M \& Lamour SA 2007 Androgenic regulation of novel genes in the epididymis. Asian Journal of Andrology 9 545-553. (doi:10.1111/j.1745-7262.2007.00316.x)

Rossi AG \& Aitken RJ 1997 Interactions between leukocytes and the male reproductive system. The unanswered questions. Advances in Experimental Medicine and Biology 424 245-252.

Seiler P, Cooper TG \& Nieschlag E 2000 Sperm number and condition affect the number of basal cells and their expression of macrophage antigen in the murine epididymis. International Journal of Andrology 23 65-76. (doi:10.1046/j.1365-2605.2000.00210.x)

Serre V \& Robaire B 1999 Distribution of immune cells in the epididymis of the aging Brown Norway rat is segment-specific and related to the luminal content. Biology of Reproduction 61 705-714. (doi:10.1095/ biolreprod61.3.705)

Shale M \& Ghosh S 2009 How intestinal epithelial cells tolerise dendritic cells and its relevance to inflammatory bowel disease. Gut $\mathbf{5 8}$ 1291-1299. (doi:10.1136/gut.2006.098475)

Shehu-Xhilaga M, Kent S, Batten J, Ellis S, Van der Meulen J, O'Bryan M, Cameron PU, Lewin SR \& Hedger MP 2007 The testis and epididymis are productively infected by SIV and SHIV in juvenile macaques during the post-acute stage of infection. Retrovirology 4 7. (doi:10.1186/17424690-4-7)

Shum WW, Da Silva N, McKee M, Smith PJ, Brown D \& Breton S 2008 Transepithelial projections from basal cells are luminal sensors in pseudostratified epithelia. Cell 135 1108-1117. (doi:10.1016/j.cell. 2008.10.020)

Shum WW, Da Silva N, Brown D \& Breton S 2009 Regulation of luminal acidification in the male reproductive tract via cell-cell crosstalk. Journal of Experimental Biology 212 1753-1761. (doi:10.1242/jeb. 027284)

Stedronska J \& Hendry WF 1983 The value of the mixed antiglobulin reaction (MAR test) as an addition to routine seminal analysis in the evaluation of the subfertile couple. American Journal of Reproductive Immunology 3 89-91.

Steinman RM \& Banchereau J 2007 Taking dendritic cells into medicine. Nature 449 419-426. (doi:10.1038/nature06175)

Steinman RM, Hawiger D \& Nussenzweig MC 2003 Tolerogenic dendritic cells. Annual Review of Immunology 21 685-711. (doi:10.1146/ annurev.immunol.21.120601.141040)

Stein-Streilein J 2008 Immune regulation and the eye. Trends in Immunology 29 548-554. (doi:10.1016/j.it.2008.08.002)

Streilein JW 1993 Immune privilege as the result of local tissue barriers and immunosuppressive microenvironments. Current Opinion in Immunology 5 428-432. (doi:10.1016/0952-7915(93)90064-Y)

Sutovsky P, Moreno R, Ramalho-Santos J, Dominko T, Thompson WE \& Schatten G 2001 A putative, ubiquitin-dependent mechanism for the recognition and elimination of defective spermatozoa in the mammalian epididymis. Journal of Cell Science 114 1665-1675.

Suzuki F 1982 Microvasculature of the mouse testis and excurrent duct system. American Journal of Anatomy 163 309-325. (doi:10.1002/aja. 1001630404) 
Tomlinson MJ, White A, Barratt CL, Bolton AE \& Cooke ID 1992 The removal of morphologically abnormal sperm forms by phagocytes: a positive role for seminal leukocytes? Human Reproduction 7 517-522.

de Witte $L$, Nabatov A, Pion $M$, Fluitsma $D$, de Jong MA, de Gruijl T, Piguet V, van Kooyk Y \& Geijtenbeek TB 2007 Langerin is a natural barrier to HIV-1 transmission by Langerhans cells. Nature Medicine 13 367-371. (doi:10.1038/nm1541)

de Witte L, Nabatov A \& Geijtenbeek TB 2008 Distinct roles for DC-SIGN + dendritic cells and Langerhans cells in HIV-1 transmission. Trends in Molecular Medicine 14 12-19. (doi:10.1016/j.molmed.2007.11.001)
Yeung CH, Nashan D, Sorg C, Oberpenning F, Schulze H, Nieschlag E \& Cooper TG 1994 Basal cells of the human epididymis-antigenic and ultrastructural similarities to tissue-fixed macrophages. Biology of Reproduction 50 917-926. (doi:10.1095/biolreprod50.4.917)

Received 30 November 2010

First decision 23 December 2010

Accepted 10 February 2011 